\title{
Hazard-Independent Stability Sensitivity Study of Steel and RC Frame Structures
}

\author{
P. Dahal ${ }^{1}$, T. Powell ${ }^{2}$, C. Mullen ${ }^{1}$ \\ 1. Department of Civil Engineering, The University of Mississippi, 106 Carrier Hall, University, MS, 38677, \\ USA \\ 2. Ingalls Shipbuilding, A Division of Huntington Ingalls Industries, Pascagoula, MS, 39568, USA \\ E-mail: pdahal1@go.olemiss.edu
}

Received: 6 September 2018; Accepted: 1 October 2018; Available online: 1 March 2019

\begin{abstract}
Structural stability relates directly to the robustness of the system even against the abnormally large load or an unexpected event which might cause perturbation- changes from the normal state of the structural system- from significant damage. This study aims to examine the sensitivity of frame systems (primarily steel moment resisting frame systems) to the initial damage and second-order geometric effects, that may arise as a result of the design load and abnormally large load coming from the unexpected event. Incremental analysis is used to track the development of second-order effects. Planar Frame models are first examined to establish the patterns of the stiffness losses occurred with various cases of hazard-independent damages. The comparison of the anticipated behavior on Reinforced Concrete (RC) frame systems is investigated through buckling analysis of steel and RC frame systems. Observing the patterns, the study is extended to a 3D model, four-story moment frame structure, located in a coastal area and exposed to a design hurricane event, thereby addressing multi-hazard issues. The impact from the amount and location of the hazard-independent damage as well as the complexity of the frame system is studied for steel frame system which generates the overall idea of individual member perturbations and stability failure of the system, as a whole.
\end{abstract}

Keywords: Stability sensitivity; Hazard-independence; Damage scenarios.

\section{Introduction}

Stability of any structural system is defined by its ability to not be affected by the perturbations occurring in the system [1]. More specifically, a system should not respond disproportionately if it is subjected to the changes in form of initial displacement, loadings, and damages. However, with the changes in the scenario and the occurrence of unexpected extreme loading conditions, the ability of the systems to resist the perturbations changes and will induce the imbalance in the structural response.

Balling and Lyon [2] studied the significance of accounting for second-order geometric effects. This work illustrates the percentage of the structural response that is controlled by both the elastic stiffness and geometric stiffness matrices for an example problem. Their studies show that the geometric stiffness matrix controls approximately 30\% of the structural response. Similarly, Cortes, Liu, and Francisco [3] investigated the robustness of several steel framing strategies. The researchers modeled a 4 - story steel framed building system and investigated the robustness of the structure by proposing several hypothetical $1^{\text {st }}$ - floor column removal cases. They employed a typical load (includes dead, live and notional loads). Their study found that the building was fairly robust. Only a few structural members exceeded their design capacities under the column removal scenarios, and replacing with stiffer members could not destroy the stability of the system. This motivates for the consideration of higher magnitude lateral loads. Thus, the critical lateral load might be the load creating the instability of the structure and questioning the robustness. Additionally, MacRae, Kimura, and Roeder [4] examined the effect of column stiffness on the seismic behavior of a braced frame. Their study provides insightful information on the relationship between the column stiffness ratio and the drift concentration of a particular floor and motivates for the concept of hazard- independent damage study. Another work by Li, Song, \& Van De Lindt [5] stated that the P-Delta effects, strength, and stiffness degradation of components and loading history mainly contribute to the degradation of structural collapse capacity. Their study shows that instability or collapse is not a high concern when subjected to a mainshock earthquake only. However, a large decrease in the collapse resistance of the structure is seen when subjected to an aftershock following the mainshock. This study depicts the loss of stability after a damaging event and illustrates how the perturbed system now responds to the loading and hence is the prime motivation for the work presented in this paper. Moreover, Sezen and Akah [6] performed collapse 
analysis and testing of an existing building. The existing four-story steel building is instrumented and physically tested by removing one of the first story columns from the perimeter frame. The results demonstrated by SAP 2000 were very irrelevant as compared to the field results. These discrepancies are attributed to the fact of not considering the load redistributions in the 2-D model. The study gives a reason to pursue this work to explore what might have happened as a result of distributed damage.

Stability Sensitivity of the steel frames is studied in this paper to address the effects. As the safe and effective design of steel building structures considers a variety of limit states, it is strength design that receives the most significant amount of consideration while accounting stability. To properly define strength design of steel structures, it is necessary first to quantify the specifically applied load to the corresponding structure or structural element. In doing so, it is possible to determine the causes and effects of the load. In order to resist the load effect, the structural members must possess the required strength.

This paper is an ultimate consequence of a work which includes finite element modeling procedure to capture the sensitivity of steel moment frames to second-order geometric effect and hazard-independent damage. Hazard independence allows investigation of a multitude of damage events and avoids labor intense damage specific calculations. The study is focused on how system perturbations are aggravated by the damage. Thus, it is a robust method for detecting weaknesses of a frame system to damage scenarios.

General stability requirements are followed as mentioned in AISC [7] specifications. Flexural, shear and axial member deformations, and all other deformations that contribute to the displacements of the structure, secondorder effects (both $P-\Delta$ and $P-\delta$ effects), geometric imperfections, stiffness reduction due to inelasticity and uncertainty in stiffness and strength are considered. Influence of slabs is not considered in the analysis. The previous work by Sideri, J., Mullen, C., Gerasimidis, S., \& Deodatis, G. [8] demonstrates the influence of slab contribution in the analysis.

\section{Methodology}

To begin the investigation of the stability of steel frame systems, the analytical finite element models of the frame systems are developed, validated and implemented to the computational models developed using ABAQUS/CAE [9] and SAP 2000.

\subsection{Analytical FEA development \& verification}

To begin the investigation of the stability of steel frame systems, an analytical finite element model of a simple portal frame is developed [10]. A multiplicative hazard-independent damage term, $\alpha$, is introduced in the bending resistance terms of the left column. To ensure the application of both the nonlinear geometric effects and the $\alpha$ term, analytical finite element assembly of the portal frame is programmed in Wolfram Mathematica and elastic critical buckling load analyses [11] are performed. Upon verification of the elastic critical buckling load result, the script is then generalized to provide an ability to determine the critical buckling load of any fixed-base portal frame. As a final step in this analysis, $\alpha$ is utilized to account for scenarios in which the bending resistance of the left column is limited to the fractions of its virgin capacity. Again, elastic critical buckling load analyses are performed and the effect of the hazard-independent damage on the buckling load is noted. Lastly, the finite element software, MASTAN2 and SAP2000, are chosen to verify the accuracy of the Wolfram Mathematica script [12].

\subsection{Scope of models}

Several Computational models of steel portal frames were developed using ABAQUS/CAE and SAP 2000. The models are based on AISC and premised on ductile design of steel structures [13].

\subsubsection{Simple portal frame}

Initial investigations are done on a "Feasible” fixed-base portal frame (Figure 1). It is subjected to several values of damage ( $0 \%$ to $30 \%$ ). Two load cases are investigated. The first load case is the 'constant lateral load - ramped vertical load' whereas the second load case is the 'constant vertical load -ramped lateral load.' The lateral load ramp limit is $100 \mathrm{Kips}$, and the vertical load ramp limit is the critical buckling load $\left(P_{c r}=3530\right.$ kips $)$. Virgin State, $10 \%$ of critical buckling load with varying values of damage and $30 \%$ damage with varying values of constant vertical loads are observed in each load case for the lateral displacement.

\subsubsection{Four-story two bay simple planar frame system}

The investigations are then performed on a 4 Story-2 Bay fixed-base frame (Figure 2a) -144" high Columns and 300" long beams. Only a single-case load, i.e., constant gravity loads and the lateral load ramped to "reasonable" value, is applied. Load development from ASCE 7 is followed, where the dead load is from frame, slabs, and façade, and the live load is from 'office' and 'roof' types. The frame system is designed as in high-velocity wind regions to help to determine realistic load scenario within design spectrum. Elastic critical "system” buckling Load 
is analyzed by examining the first three buckling modes. Three hazard-independent damage scenarios are studied: 'exterior columns damage', 'interior column damage', and 'all second-floor columns damage.' Additional 2D model of RC frame system is also developed following the ASCE 7 and the standards from American Concrete Institute (ACI). The main objective is to identify the need of doing the similar study for the RC frame systems.

\subsubsection{D frame system}

The investigations are then performed on a series of moment frames (Figure 2b), which are the characteristic design of low-rise building structure found in high-velocity wind regions. Planar model frames are utilized with the addition of girders (7 Frames @ 20'). Identical load case from previous model (planar frame model) is employed. The analyzed hazard-independent damage scenarios are 'all first floor column damage', 'longitudinal exterior Face damage with intensity 1 to 5' and 'concentrated interior damage with intensity 1 to 5'. The damage scenarios are defined based on the real life scenarios events; like the exterior blast and concentrated wind pressure for exterior face damage and interior blast for the interior damage. Similarly, the intensity is categorized based on the level of damages in the system level.

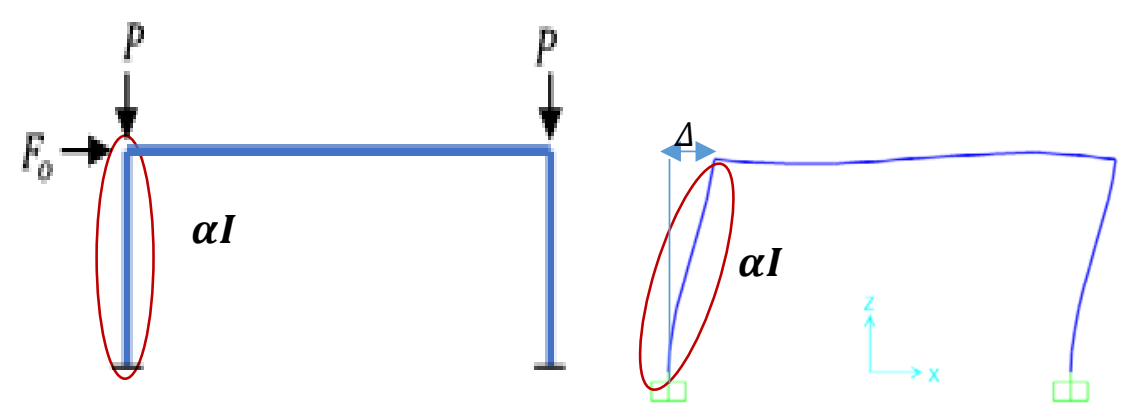

Figure 1. Non-deformed and deformed Shape with damage scenario- simple portal frame ( $\Delta$ denotes lateral deflection; stiffness discussed is along lateral direction)

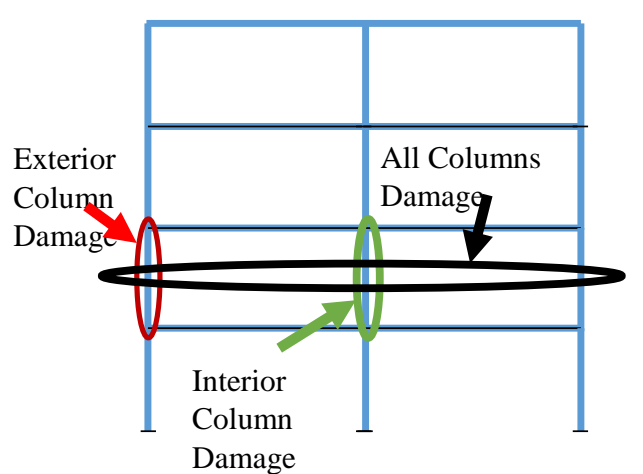

(a)

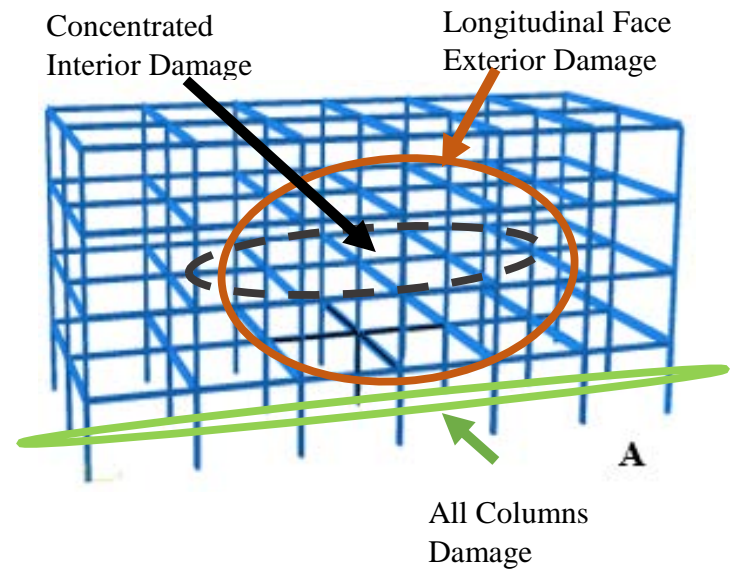

(b)

Figure 2. Non-deformed shape with damage scenarios- (a) Planar frame (b) 3D frame assembly

\section{Results and discussions}

The formulae of analytical FEA are within the acceptable range of error, thus, successful validation is achieved. Additionally, it is found that the damage impacts critical load, however it does not reveal that the axial stiffness remains unaffected.

Regarding computational investigations of different models, following results are obtained.

\subsection{Simple portal frame model}

Limits for the axial load applied to beam-column elements that cause the bifurcation of equilibrium and excite second-order geometric effects are calculated. These limits are known as elastic critical buckling loads. Results of the study indicate that the damage reduces the elastic critical buckling load. Lastly, load versus deflection 
curves (Figure 3) obtained illustrates the buckling of the portal frame and shows that the small increase in the applied loads results in a disproportionate instability. This depicts how the second-order geometric effects and hazard-independent damage affects the system response and may lead to instability.

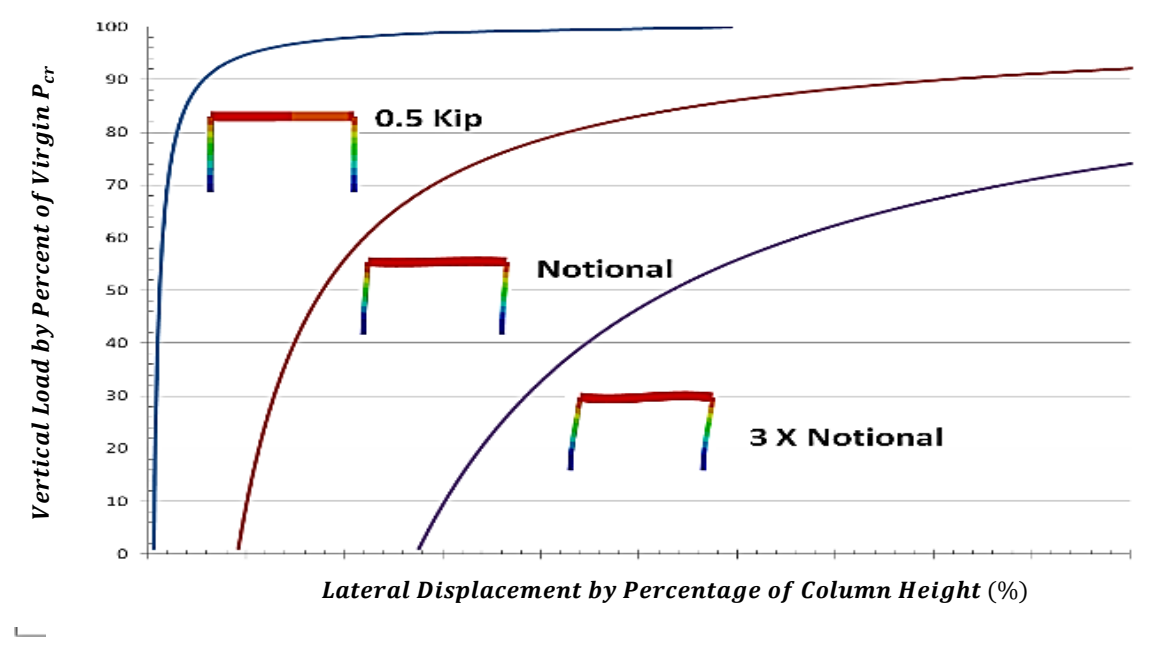

Figure 3. Vertical Load by the percent of Virgin $P_{c r}$ versus Lateral Displacement by the percent of Column Height (Virgin State)

\subsection{Simple planar frame model}

Analyzing the second model shows that the exterior column damage is not found to indicate any stability sensitivity, interior one indicates slight stability sensitivity, and all second-floor column damage indicates the highest stability sensitivity. Similar is the case with RC Frame Structures. However, the greater value of buckling load of RC frame (Table 1) shows its lower sensitivity to stability as compared with steel one. Figure 4 depicts that the stiffness loss occurred by imparting damage to the exterior columns is rarely noticeable. However, Figure. 5 depicts that about $30 \%$ of the stiffness loss is occurring on the fourth floor after imposing $100 \%$ damage to the interior column, which is noticeably greater as compared to the damage imposed in exterior column. And, the extent of stiffness loss is even larger for all second floor column damage case (Figure. 6). Thus, damage scenarios involving the damage to the interior column or all columns on the $2^{\text {nd }}$ floor could lead to the instability of the structure. The second-floor columns are taken for the consideration owing to their vulnerability from the study of their mode shapes.

Table 1. Critical elastic buckling loads for steel and RC planar frames.

\begin{tabular}{lll}
\hline & Steel Frame System & RC Frame System \\
\hline Buckling Mode 1 Load (in Kips) & 1753.5 & 8015 \\
Buckling Mode 2 Load (in Kips) & 2820 & 9750 \\
Buckling Mode 3 Load (in Kips) & 3460 & 12113 \\
\hline
\end{tabular}

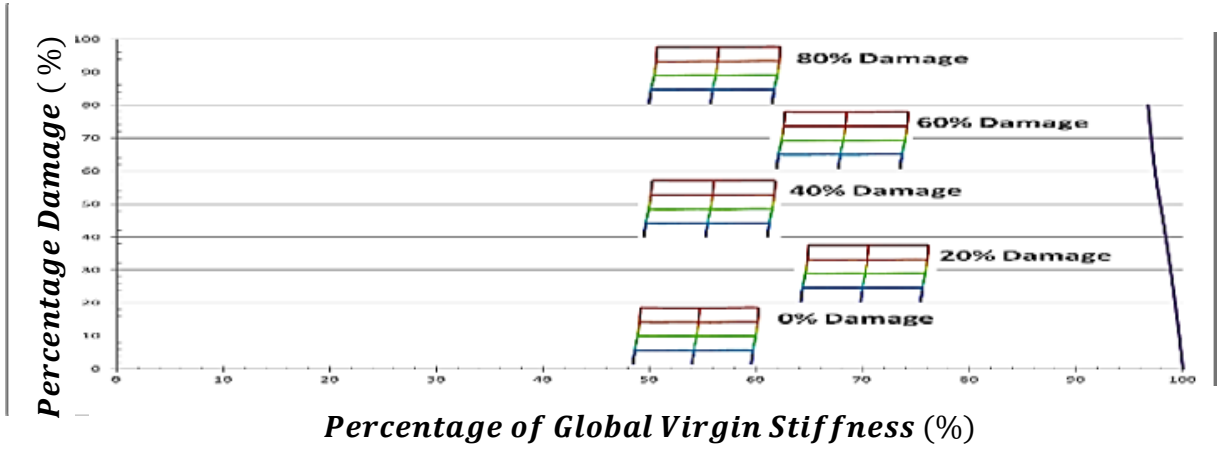

Figure 4. Global Stiffness Loss Versus Percent Damage (Exterior Column Damage) of simple planar steel frame system 


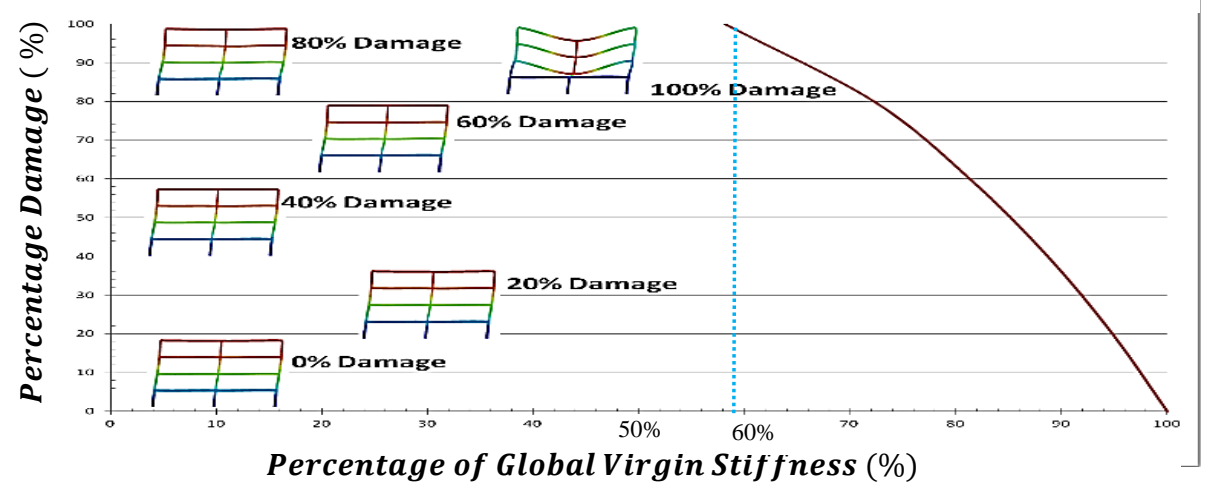

Figure 5. Global Stiffness Loss Versus Percent Damage (Interior Column Damage) of simple planar steel frame system.

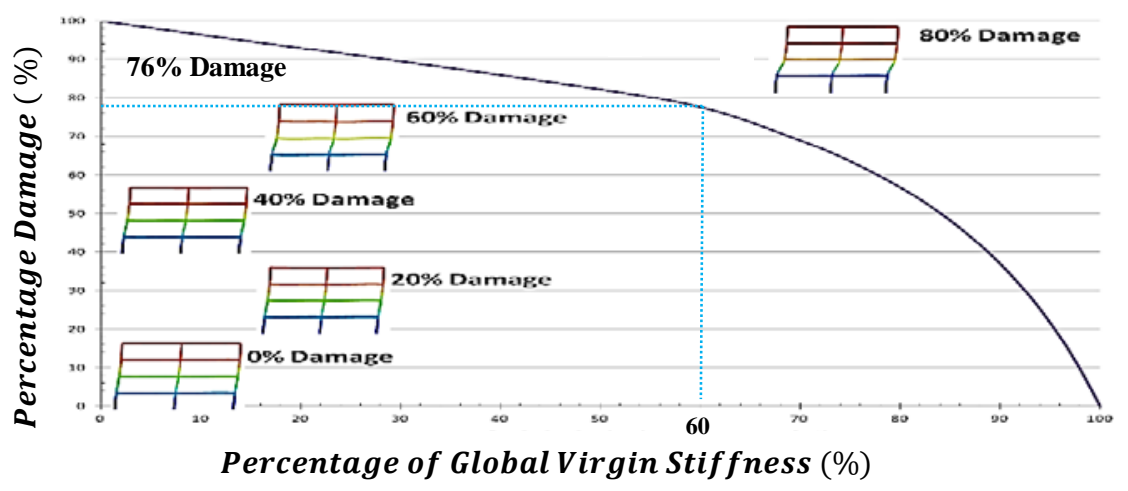

Figure 6. Global Stiffness Loss Versus Percent Damage (All first floor Column Damage) of simple planar steel frame system.

\subsection{D assembly model}

The higher Sensitivity of the structure's stability is found in centralized interior and all 1st-floor column damage scenarios. From Figure. 7, it is clearly seen that only a small effect on the global stiffness has occurred in distributed exterior longitudinal face damage from any damage intensity. However, there is a greater, somehow linear stiffness loss pattern even in lower damage intensity in case of all first-floor columns damage (Figure. 8) and concentrated interior damage cases (Figure. 9). The results of this study are strictly controlled by the application of the lateral load. This loading is only applied perpendicularly to the longitudinal face of the frame because the system is not braced for the loadings that are perpendicular to the transverse face of the frame.

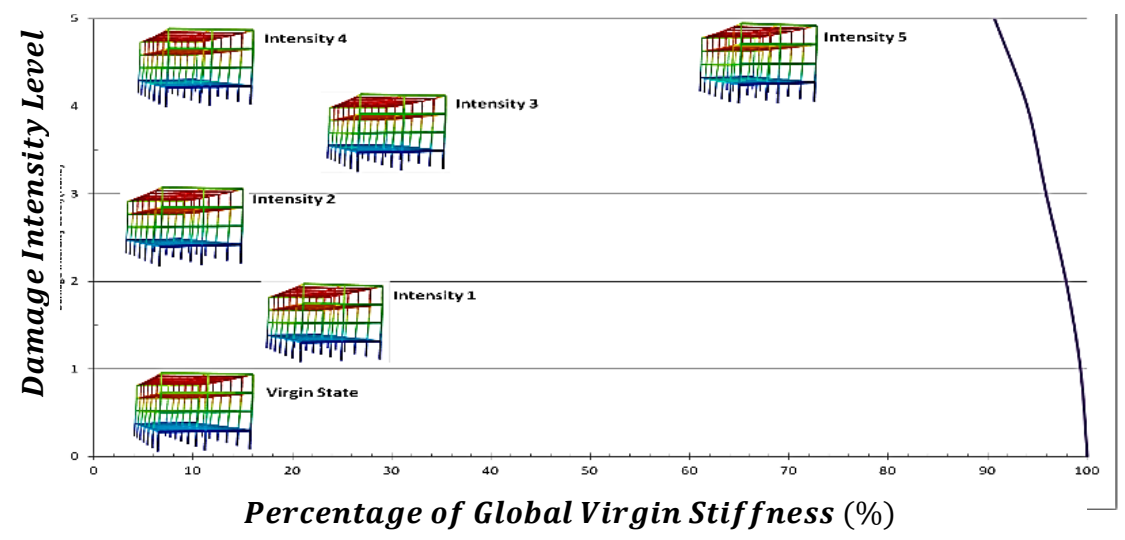

Figure 7. Global Stiffness Loss versus Damage Intensity Level (Distributed Exterior Longitudinal Face Damage) of 3D Steel frame system. 


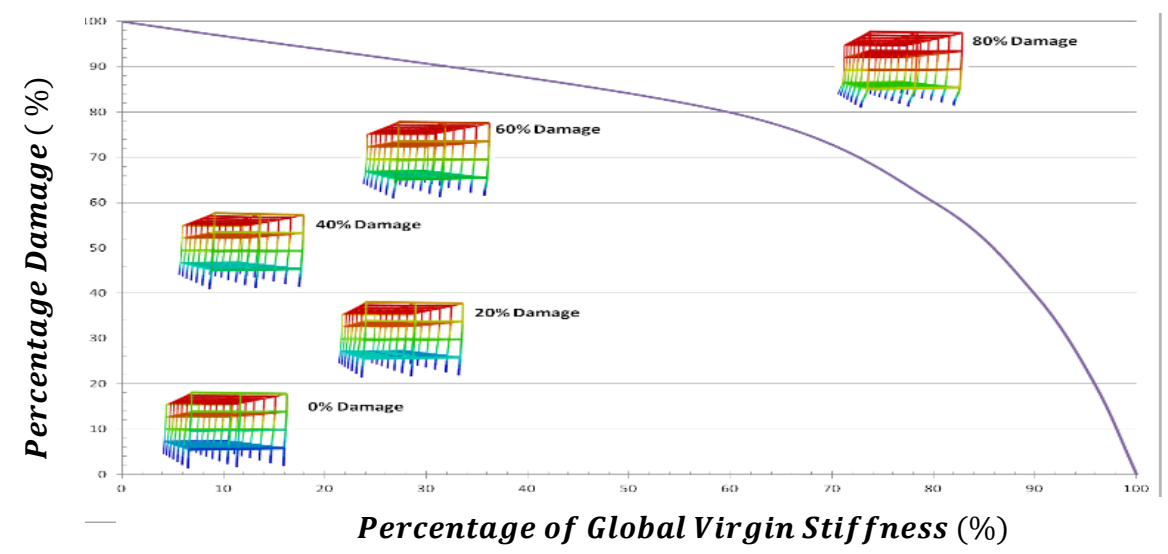

Figure 8. Global Stiffness Loss versus Percentage Damage (All First-Floor Columns Damage) of the 3D steel frame system.

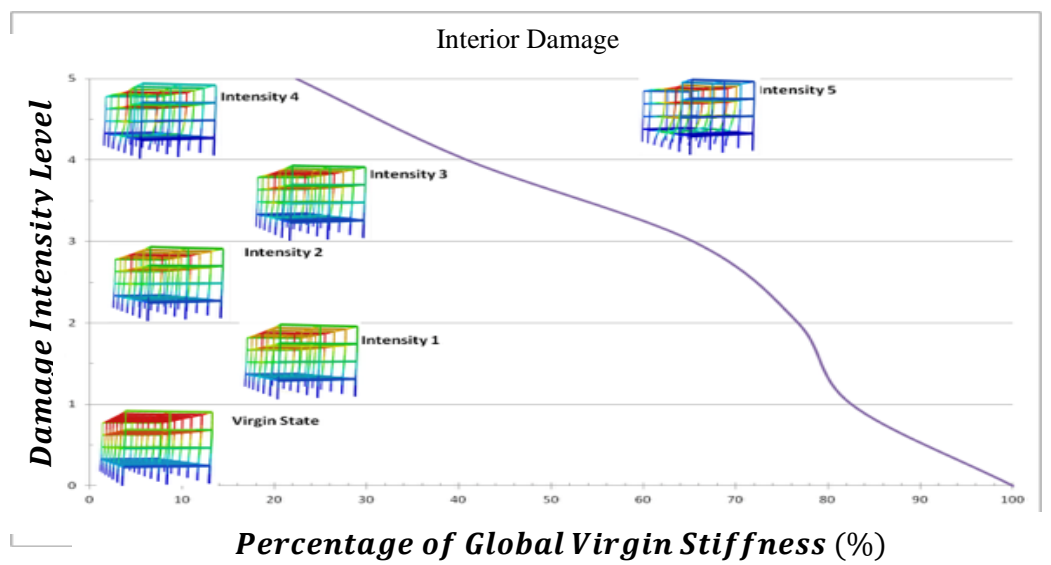

Figure 9. 4th-Floor Stiffness Loss versus Damage Intensity Level (Concentrated Interior Damage) of the 3D steel frame system.

\section{Conclusions and recommendations}

The generalized elastic buckling load analysis of the portal frame validated the accurate use of hazardindependent damage approach, and hence can be further used for developing the tools based on measurement science needs for the structural design. From, 4 story-2 Bay frame, it is concluded that the stability of the system indicates sensitivity to the interior damage and the entire floor (all columns) damage, but not to the exterior column damage under the studied load scenario. Similarly, characteristic wind design frame assembly helps to purport that the centralized interior and all floor-columns damage have the high possibility of instability as compared to the longitudinal exterior face damage. To conclude, the results show the nature of damage potential (Stiffness Loss) involving nonlinear geometric elastic response FE simulations of the subsystem and a system of increasing complexity not only of the frame but also of the possible damage scenarios.

This research can be more expanded with broader steel frame assemblies by introducing the effect of bracing. Additionally, the larger scope of applied loadings can be studied by including the direction of lateral loading. Additional damage scenarios can be incorporated, and applied damage can be assimilated for more refinement, and working for robustness of any structures. Moreover, it will be helpful for analyzing the damage potential from the components to the system as a whole. Regarding the further investigation of the following work, it is envisioned to build a robust framework to co-relate hazard-independent approach with the four important parameters of Objective Resilience (OR) - Robustness, Resourcefulness, Redundancy, and Recovery i.e., (4Rs). The work can be targeted for the select set of buildings and performing analysis to quantify and preparing tools to assist improving seismic resiliency of the buildings.

\section{Acknowledgement}


This work was partly supported by the University of Mississippi, Department of Civil Engineering and Graduate School through funding received under Graduate Research Assistantship. We will like to thank them and are deeply indebted to the School of Engineering, as well, for assisting us in conducting the research. We would also like to show our gratitude to the colleagues from the University of Mississippi for sharing their pearls of wisdom with us during the different workshops and seminars. We are also immensely grateful to the reviewers for their comments on the earlier version of the manuscript because of which we are able to prepare the best and the concise version of our research work.

\section{References}

[1] Chen WF, Lui EM. Structural stability theory and implementation. New York: Prentice Hall; 1993.

[2] Balling RJ, Lyon JW. Second-order analysis of plane frames with one element per member. Journal of Structural Engineering. 2010;137(11):1350-1358.

[3] Cortes G, et al. Framing Strategies for Robustness in Steel Buildings. (Final Report submitted to AISC). 2015.

[4] MacRae GA, Kimura Y, Roeder C. Effect of column stiffness on braced frame seismic behavior. Journal of Structural Engineering. 2004;130(3):381-391.

[5] Li Y, Song R, Van De Lindt JW. Collapse fragility of steel structures subjected to earthquake mainshockaftershock sequences. Journal of Structural Engineering. 2014;140(12):04014095.

[6] Sezen, Halil, and Ebiji A. Akah. Collapse Analysis and Testing of an Existing Building, Structures Congress 2015 - Proceedings of the 2015 Structures Congress, (2015), pp. 1078-1089.

[7] American Institute of Steel Construction. Manual of steel construction, 15 ${ }^{\text {th }}$ Edition. Chicago: AISC; 2016.

[8] Sideri J, Mullen CL, Gerasimidis S, Deodatis G. Distributed column damage effect on progressive collapse vulnerability in steel buildings exposed to an external blast event. Journal of Performance of Constructed Facilities. 2017;31(5):04017077.

[9] Simulia. ABAQUS theory manual. Dassault Systems Simulia Corporation; 2012.

[10] Hughes T. The finite element method. Mineola: Dover Publications; 1987.

[11] Galambos T. Guide to stability design criteria for metal structures. New York: John Wiley \& Sons; 1998

[12] Powell T. Stability sensitivity of low-rise steel-moment resisting frame buildings to hazard-independent damage. [Master's Thesis in partial fulfillment of the requirements for a Master's degree]. Department of Civil Engineering, The University of Mississippi, University, Mississippi, US.

[13] Bruneau M, et al. Ductile design of steel structures. New York: McGraw Hill;2011.

(C) 2019 by the author(s). This work is licensed under a Creative Commons Attribution 4.0 International License (http://creativecommons.org/licenses/by/4.0/). Authors retain copyright of their work, with first publication rights granted to Tech Reviews Ltd. 